\title{
Shorter Adult Height is Associated with Poorer Cognitive Performance in Elderly Men with Type II Diabetes
}

\author{
Rebecca K. West ${ }^{\mathrm{a}, *}$, Ramit Ravona-Springer ${ }^{\mathrm{b}}$, Anthony Heymann ${ }^{\mathrm{d}}$, James Schmeidler ${ }^{\mathrm{a}}$, \\ Derek Leroith $^{\mathrm{e}}$, Keren Koifman ${ }^{\mathrm{b}}$, Elizabeth Guerrero-Berroa ${ }^{\mathrm{a}}$, Rachel Preiss ${ }^{\mathrm{b}}$, Hadas Hoffman ${ }^{\mathrm{b}}$, \\ Jeremy M. Silverman ${ }^{\mathrm{a}, \mathrm{c}}$ and Michal Schnaider Beeri ${ }^{\mathrm{a}, \mathrm{b}}$ \\ ${ }^{a}$ Department of Psychiatry, Icahn School of Medicine at Mount Sinai, New York, NY, USA \\ ${ }^{\mathrm{b}}$ The Joseph Sagol Neuroscience Center, Sheba Medical Center, Ramat Gan, Israel \\ ${ }^{\mathrm{c}}$ James J. Peters Veterans Affairs Medical Center, Bronx, NY, USA \\ ${ }^{\mathrm{d}}$ Maccabi Healthcare Services, Tel-Aviv, Israel \\ ${ }^{\mathrm{e}}$ Division of Medicine, Endocrinology, Diabetes, and Bone Disease, Department of Medicine, Icahn School \\ of Medicine at Mount Sinai, New York, NY, USA
}

Accepted 1 October 2014

\begin{abstract}
We studied the relationship of adult body height with five cognitive outcomes (executive functioning, semantic categorization, attention/working memory, episodic memory, and an overall cognition measure) in 897 cognitively normal elderly with type 2 diabetes. Regression analyses controlling for sociodemographic, cardiovascular, and diabetes-related risk factors and depression demonstrated that in males, shorter stature was associated with poorer executive functioning $(p=0.001)$, attention/working memory ( $p=0.007)$, and overall cognition $(p=0.016)$, but not with episodic memory $(p=0.715)$ or semantic categorization $(p=0.948)$. No relationship between height and cognition was found for females. In cognitively normal type 2 diabetes male subjects, shorter stature, a surrogate for early-life stress and poor nutrition, was associated with cognitive functions.
\end{abstract} Keywords: Cognitive performance, height, risk factors, type 2 diabetes mellitus, vascular dementia

\section{INTRODUCTION}

In the absence of disease-modifying treatments for dementia and cognitive decline, there is a demand to understand the etiology of the disease from a prevention perspective. Risk factors examined in the years prior to dementia ascertainment may be contaminated by the imminent dementia process itself. However, midlife risk factors for dementia, which are measured decades before dementia diagnosis, also do not fully predict the disease [1]. This may suggest that childhood factors may contribute to this group of neurodegenerative diseases [2]. Adult body height, although affected

*Correspondence to: Rebecca West, M.A., Department of Psychiatry, Box 1230, Mount Sinai School of Medicine, One Gustave L Levy Place, Box 1230, New York, NY 10029, USA. Tel.: +1 212 659 5603; Fax: +1 212659 5626; E-mail: rebecca.west@mssm.edu. by genetics [3], is a surrogate for early life illness, stress, and poor nutrition [3], and has been associated with adult cognitive performance [4-6]; and in some studies, with Alzheimer's disease (AD) and vascular dementia [7-9]. Anthropometric measures associated with height, including head circumference, leg length, knee height, and arm span have also been found to be related to adulthood cognition [15-19]. Head circumference in particular may be an indicator of brain reserve, as well as childhood deprivation and lower education attainment, which may impact later-life cognitive functioning $[15,16]$. Height is also associated with cardiovascular disease [10] and type 2 diabetes (T2D) $[11,12]$. These conditions, in turn, are associated with dementia $[13,14]$.

Height has been associated with both T2D [20] and cognition [4-9], and T2D has been associated with 
early life conditions [21]. However, the relationship between height and cognitive function in T2D has not been investigated, and there is very limited information about the relationship between height and specific cognitive domains. We thus examined this relationship in a large cohort of T2D elderly participating in the Israel Diabetes and Cognitive Decline (IDCD) study, an investigation of the relationships of long-term T2D-related characteristics with cognitive decline. The study is a collaboration between the Icahn School of Medicine at Mount Sinai, NY, the Sheba Medical Center, Israel, and the Maccabi Healthcare Services (MHS), Israel.

\section{METHODS}

The study is based on the baseline assessments of the IDCD study [22, 23], which has as its primary goal to identify characteristics within $\mathrm{T} 2 \mathrm{D}$, that increase the risk of cognitive decline and dementia. Participants in the IDCD study were randomly selected from the approximately 11,000 T2D individuals in the MHS Diabetes Registry, maintained since 1998 [22]. The design and rationale of the IDCD has been described in detail elsewhere [22-24]. Briefly, participants included in the study had confirmed T2D, were initially cognitively normal (based on a Clinical Dementia Rating scale [25] score of zero and a multidisciplinary consensus conference), were above the age of 65 , lived in central Israel, were fluent in Hebrew, had at least one informant, did not have any neurological or psychiatric conditions potentially affecting cognition (e.g., schizophrenia, stroke), and had at least two HbA1c assessments. The IDCD has recruited 1,288 subjects, of which $8.5 \%$ (110 individuals) refused to participate and $21.9 \%$ (282 individuals) were excluded by eligibility criteria [the vast majority $(86 \%)$ due to cognitive impairment]). The remaining 897 completed a baseline evaluation. The IDCD study is approved by the Mount Sinai, Sheba, and MHS IRB committees.

Participants were assessed by a physician experienced in assessment and diagnosis of dementia and by a neuropsychologist, who administered a broad neuropsychological battery [22-24], which was the basis for the outcome measures. Factor analysis summarized the neuropsychological measures into four domains: episodic memory (immediate recall, delayed recall, and recognition), executive functioning (Trails $\mathrm{A}$ and Trails B, constructional praxis, and digit symbol), semantic categorization (similarities, letter fluency, category fluency), and attention/working memory (dia- mond cancellation, digit span forward, and digit span backwards). The neuropsychological tests scores were transformed into $\mathrm{Z}$ scores (reversed if necessary so that high represented good cognition) and summed for each domain. An overall cognition measure summed the scores of all four domains.

Regression analyses including all participants, and subsequently stratified by sex, controlling for sociodemographic (years of education, age, region of birth), cardiovascular (total, LDL, and HDL cholesterol, triglycerides, creatinine, and hypertension), depression (Geriatric Depression Scale positive answers), and T2D characteristics (time in the MHS diabetes registry [an approximation of duration of T2D], hemoglobin $\mathrm{A} 1 \mathrm{c}$ [HbA1c], and T2D medications) that are associated with cognition, were performed to examine the associations of height with the cognitive domain and overall cognition. An interaction analysis including males and females, controlling for all covariates, tested a sex difference in the effect of height on cognition. We also performed sex-stratified analyses of covariance (ANCOVA) for the quartiles of height, to estimate means of the cognitive measures controlling for the same covariates, and tested the linear contrasts. Finally, we performed general linear models with and without interaction terms to determine how stature modifies the association of risk factors with cognitive performance. The extent of the interaction of height (in quartiles) with groups of demographic, cardiovascular, and diabetes risk factors on cognition-we chose to use groups of risk factors rather than each risk factor singly to refrain from a large number of multiple comparisons-was assessed.

Height was measured with the subject standing barefoot, to the nearest centimeter, by a study physician. For the cardiovascular and HbA1c covariates, we used the average of all the subject's measurements available in the MHS Diabetes Registry.

\section{RESULTS}

Characteristics of the sample, stratified by sex and by their respective height quartiles, are presented in Table 1. For males, years of education increased with increasing height, and age decreased by increasing height. There were no significant differences between height quartiles for females, on demographic, cardiovascular, diabetes, or depression variables. In this sample, males had significantly more years of education $(p=0.009$, mean difference 0.62 years), and depressive symptoms $(p<0.001$, mean 


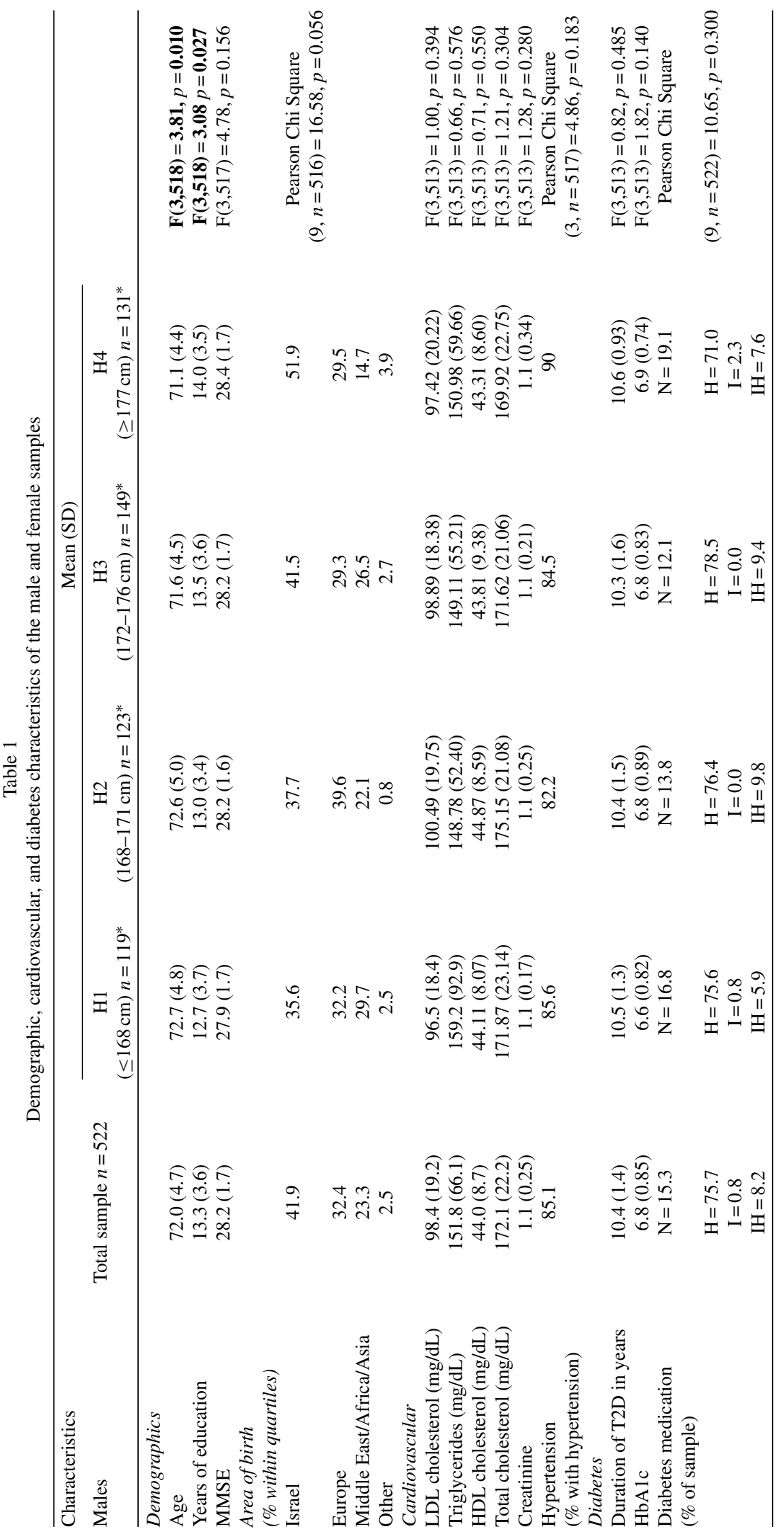




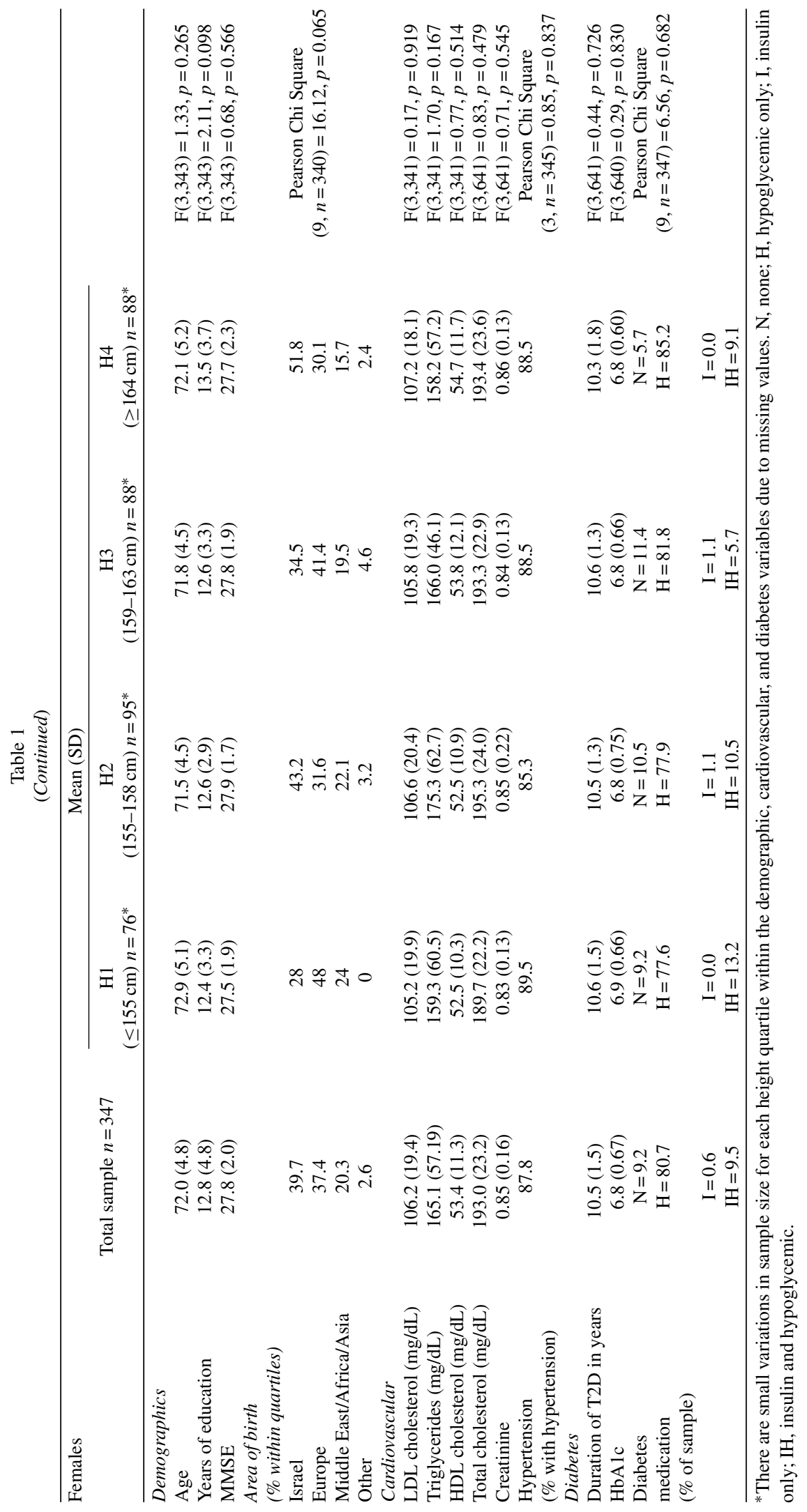


difference 0.62 [out of a maximum score of 15]), and higher creatinine levels $(p<0.001$, mean difference $0.25 \mathrm{mg} / \mathrm{dL}$ ), compared to females. Females had significantly higher cholesterol $(p<0.001$, mean difference $20.2 \mathrm{mmol} / \mathrm{L})$ HDL $(p<0.001$, mean difference $9.4 \mathrm{mg} / \mathrm{dL})$, LDL $(p<0.001$, mean difference $7.9 \mathrm{mg} / \mathrm{dL})$, and triglycerides ( $p=0.0011$, mean difference $14.1 \mathrm{mg} / \mathrm{dL}$ ), compared to males.

Linear regression analyses on the whole sample, controlling for socio-demographic, cardiovascular, depression, and T2D covariates, showed that height was significantly associated with attention/working memory $(\beta=0.121, \mathrm{t}(825)=2.721$, $p=0.007)$ and executive functioning $(\beta=0.139$, $\mathrm{t}(824)=3.401, \quad p=0.001), \quad$ and overall cognition $(\beta=0.098, t(825)=2.421, p=0.016)$, semantic categorization $(\beta=-0.003, \mathrm{t}(825)=-0.065, p=0.948)$ or episodic memory $(\beta=0.017, \mathrm{t}(825)=0.366$; $p=0.715)$.

To assess the contribution of sex to the relationship between height and cognition, interaction analysis including males and females, controlling for all covariates, was used to evaluate a sex difference in the effect of height on cognition. There was a significant interaction between sex and height for overall cognition $(\beta=-0.205, \mathrm{t}(825)=-1.96$, $p=0.050)$ and semantic categorization $(\beta=-0.220$, $\mathrm{t}(825)=-2.04, p=0.041$, but not executive functioning $(\beta=-0.147, \quad \mathrm{t}(824)=-1.36, \quad p=0.175)$, episodic memory $(\beta=-0.160, \mathrm{t}(825)=-1.28$, $p=0.200)$ or attention/working memory $(\beta=-0.091$, $\mathrm{t}(825)=-0.77, \quad p=0.443)$. As a sex interaction was not originally hypothesized, screening for this interaction has poor power so $p$-values even as large as 0.20 may suggest that the effect of height on cognition differs depending on sex [26].

To further evaluate sex differences in the association of height with cognition, sex-stratified linear regression analyses were run, controlling for socio-demographic, cardiovascular, depression, and T2D covariates, stratified by sex. Results showed that for males, height was significantly associated with attention/working memory $(\beta=0.096$, $\mathrm{t}(493)=2.271, \quad p=0.024), \quad$ executive functioning $(\beta=0.133, \quad \mathrm{t}(493)=3.52, \quad p<001), \quad$ and overall cognition $\quad(\beta=0.108, \quad \mathrm{t}(493)=2.93, \quad p=0.004)$, but not with semantic categorization $(\beta=0.045$, $\mathrm{t}(493)=1.17, \quad p=0.244) \quad$ or episodic memory $(\beta=0.038, \mathrm{t}(493)=0.86, p=0.393)$.

However, for females, height was not significantly associated with any of the cognitive functions; attention/working memory $(\beta=0.075$, $\mathrm{t}(317)=1.43, \quad p=0.153), \quad$ executive functioning $(\beta=0.053, \mathrm{t}(316)=1.10, p=0.270)$, overall cognition $(\beta=0.020, \mathrm{t}(317)=0.43, p=0.671)$, semantic categorization $(\beta=-0.55, \mathrm{t}(317)=-1.18, p=0.235)$, or episodic memory $(\beta=-0.015, \mathrm{t}(317)=-0.28$ $p=0.781$ ).

The estimated means adjusted for the covariates for quartiles of height, and the results of the ANCOVAs and linear regressions are shown in Table 2. Results were very similar to those found in the regression analyses such that the means of cognitive functions increased (i.e., were better) with increasing height quartiles for males.

Within males, general linear models were used to determine that height modified the relationship of demographic factors (age, years of education, and area of birth) with overall cognition $(\mathrm{F}(9,500)=2.52$, $p=0.017)$ and executive functioning $(\mathrm{F}(9,500)=1.93$, $p=0.046)$. We performed additional general linear model analyses to identify the specific demographic risk factor that was modified by height. We found that height modified the relationship of years of education with overall cognition $(\mathrm{F}(3,491)=3.162, p=0.024)$, executive functioning $(\mathrm{F}(3,491)=3.257, p=0.021)$, and episodic memory $(\mathrm{F}(3,491)=2.958, p=0.032)$. Partial correlations within quartiles of height were performed for descriptive purposes (Table 3) and showed that the association of education with cognition is stronger in the shorter stature groups.

\section{DISCUSSION}

In this sample of elderly with T2D, for males, shorter stature was associated with lower overall cognition, attention/working memory, and executive functions after controlling for sociodemographic and a broad range of cardiovascular and diabetes risk factors. No relationship between height and cognition was found for females. Supporting our results, several studies have found shorter stature to be associated with higher risk of cognitive compromise (relationship found in males only [4]; relationship found in both males and females $[5,6])$, including AD and vascular dementia [7-9].

Shorter adult height is associated with smaller head circumference, which is associated with poorer cognitive reserve [18] and cognitive performance [16]. Shorter adult height and smaller head circumference may be consequences of childhood malnutrition and/or stress [3, 27]. Prenatal conditions have been found in some studies to disproportionally impact the health 


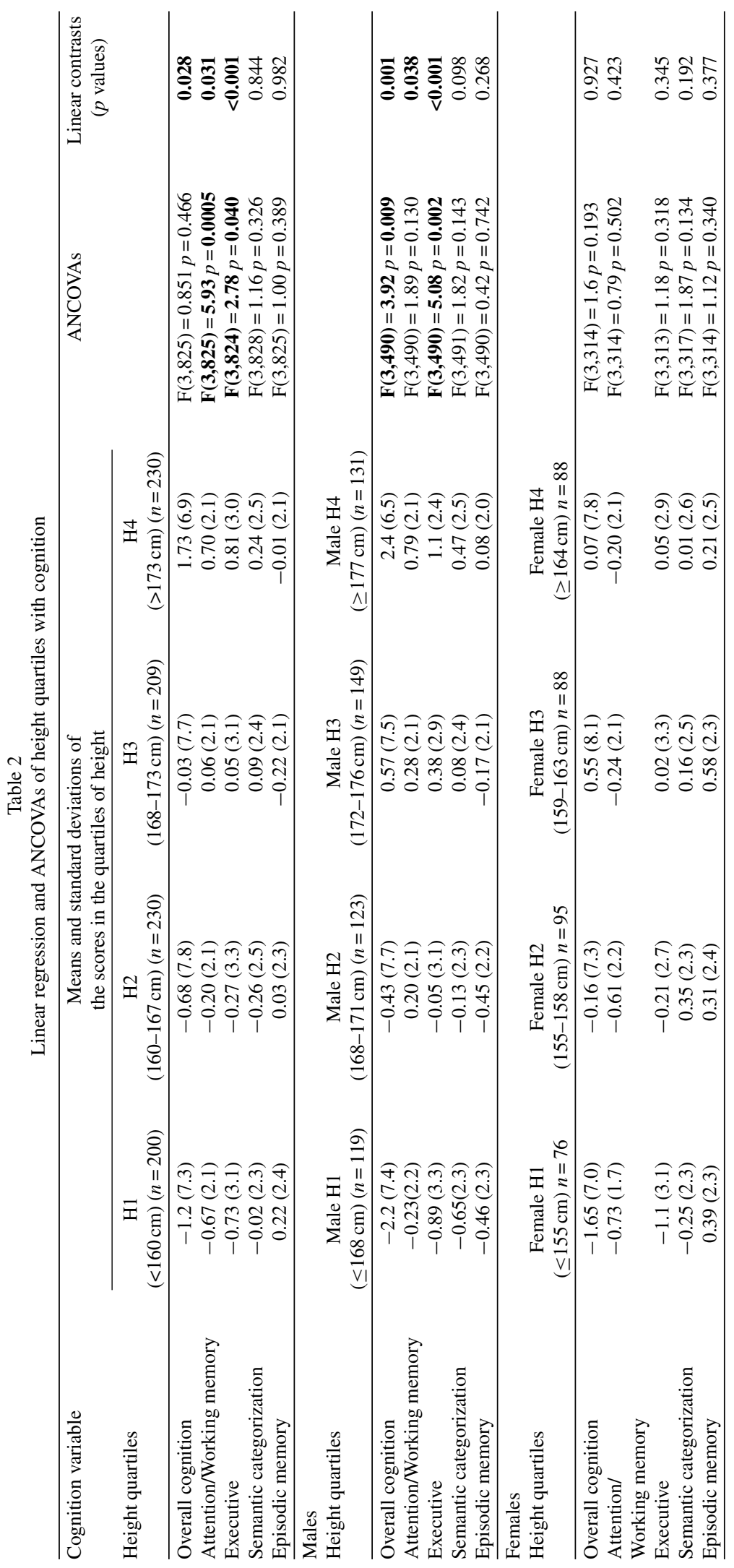


Table 3

Partial correlations between education and cognitive functions within height quartiles for males

\begin{tabular}{|c|c|c|c|c|}
\hline & H1 & $\mathrm{H} 2$ & $\mathrm{H} 3$ & $\mathrm{H} 4$ \\
\hline Overall & $r=0.580, p<0.001^{* *}$ & $r=0.511, p<0.001^{* *}$ & $r=0.524, p<0.001^{* *}$ & $r=0.316, p=0.001^{*}$ \\
\hline Attention/Working memory & $r=0.493, p<0.001^{* *}$ & $r=0.316, p=0.001^{* *}$ & $r=0.291, p=0.001^{* *}$ & $r=0.203, p=0.029^{*}$ \\
\hline Executive & $r=0.499, p<0.001^{* *}$ & $r=0.504, p<0.001^{* *}$ & $r=0.496, p<0.001^{* *}$ & $r=0.307, p=0.001^{*}$ \\
\hline Semantic categorization & $r=0.476, p<0.001^{* *}$ & $r=0.467, p<0.001^{* *}$ & $r=0.426, p<0.001^{* *}$ & $r=0.283, p=0.002^{*}$ \\
\hline Episodic memory & $r=0.212, p=0.030^{*}$ & $r=0.221, p=0.022^{*}$ & $r=0.355, p<0.001^{* *}$ & $r=0.000, p=0.996$ \\
\hline
\end{tabular}

${ }^{*} p \leq 0.05 ;{ }^{* *} p \leq 0.001$.

and mortality of males [28-31], leading to lower birth weights and higher rates of early life illness; thus height may be a better indicator of early life conditions for males than for females. Childhood stressors may predispose individuals to poorer physical and mental health [27] and may impact brain growth, limiting brain and cognitive reserve [6]. Cognitive and brain reserves allow individuals to preserve normal functioning even when brain degeneration is occurring. If shorter stature reflects poorer reserve, then clinical symptoms might develop earlier in shorter individuals. Further, overall years of education, early education, and linguistic ability promote cognitive reserve [32, 33], and lower education and linguistic ability are associated with height, likely due to malnutrition, socioeconomic conditions, and stress [27]. Within males, we found that the correlation of years of education with all cognitive domains was consistently smaller in the highest quartile of height than in the shorter three quartiles. Stature appears to modify the association between cognition and years of education, such that education is not as strongly associated with cognition in the tallest males. This suggests that in the tallest male, early childhood conditions which may have provided the opportunity for greater height, may have also contributed to greater cognitive reserve - the latter may overcome the contributions of age or education to cognitive performance.

Poor prenatal and early childhood conditions which may impact height are also likely to increase the risk of numerous health conditions, including T2D [34, 35] which has consistently been associated with dementia and AD [14]. The IDCD is focused on T2D patients only, so it was not possible to investigate whether low stature interacts with T2D status to affect deleteriously cognition. Further, there could be a genetic predisposition to cognitive impairment or dementia shared by low stature individuals that could explain this relationship.

Our study innovates by showing that height is associated with cognitive performance in T2D males, and that this relationship is apparent even within the range of normal cognitive function. Further, this study examines the relationship of height with specific cognitive domains. To our knowledge, only two other reports [36,
37] have examined the relationship between height and specific cognitive domains, none of them in the context of T2D. These studies have found low stature to be associated with poorer overall cognition and executive functioning [37], similarly to our findings, but in contrast to our findings, also with semantic categorization [36], diabetes status unknown. Consistent with our results, episodic memory, the primary cognitive domain involved in $\mathrm{AD}$ [38], was not found to be associated with height $[36,37]$. However, neither report found a relationship between attention/ working memory and height, as we have found. In the context of aging with T2D, where small vessel disease is common, low stature may be associated with accelerated development of cerebrovascular disease [39], which in turn, has been consistently associated with non-episodic memory cognitive functions such as poor executive functions and attention/working memory [38], even after controlling for cardiovascular risk factors [40] suggesting that vascular mechanisms may be contributing to the relationship of height with cognition in T2D.

Our study has limitations. The outcomes are crosssectional, with cognition assessed at a single time point. Neuroimaging or other indicators, such as genetic information, that could shed light on the contribution of height to cognition in T2D was not available. IQ was not collected as a part of this study; IQ could provide greater understanding of the contribution of stature to cognitive premorbid function. This study is strengthened by a large sample, with strong validity for T2D diagnosis and for cardiovascular variables, and a broad cognitive assessment, permitting examination of global and specific cognitive domains.

\section{ACKNOWLEDGMENTS}

This study was supported by NIA grants R01 AG034087 to Dr. Beeri and P50 AG05138 to Dr. Sano, the Helen Bader Foundation, the Leroy Schecter Foundation, and the Irma T. Hirschl Scholar award to Dr. Beeri, the American Federation for Aging Research (AFAR) Young Investigator award, and the 
Alzheimer's Association grant NIRG-11-205083 to Dr. Ravona-Springer.

Authors' disclosures available online (http://www.jalz.com/disclosures/view.php?id=2580).

\section{REFERENCES}

[1] Kivipelto M, Ngandu T, Laatikainen T, Winblad B, Soininen $\mathrm{H}$, Tuomilehto J (2006) Risk score for the prediction of dementia risk in 20 years among middle aged people: A longitudinal, population-based study. Lancet Neurol 5, 735741 .

[2] Whalley LJ, Dick FD, McNeill G (2006) A life-course approach to the aetiology of late-onset dementias. Lancet Neurol 5, 87-96.

[3] Silventoinen K (2003) Determinants of variation in adult body height. J Biosoc Sci 35 263-285.

[4] Quan SA, Jeon J, Kim D (2013) The relationship between height and cognitive function among communitydwelling elderly: Hallym Aging Study. Epidemiol Health 35, e2013002.

[5] Laitala VS, Hjelmborg J, Koskenvuo M, Räihä I, Rinne JO, Christensen K, Kaprio J, Silventoinen K (2011) Shorter adult stature increases the impact of risk factors for cognitive impairment: A comparison of two Nordic twin cohorts. Twin Res Hum Genet 14, 544-552.

[6] Abbott RD, White LR, Ross W, Petrovitch H, Masaki KH, Snowdon DA, Curb JD (1998) Height as a marker of childhood development and late-life cognitive function: The Honolulu-Asia Aging Study. Pediatrics 102, 602-609.

[7] Petot GJ, Vega U, Traore F, Fritsch T, Debanne SM, Friedland RP, Lerner AJ (2007) Height and Alzheimer's disease: Findings from a case-control study. J Alzheimers Dis 11, 337341.

[8] Beeri MS, Davidson M, Silverman JM, Noy S, Schmeidler J, Goldbourt U (2005) Relationship between body height and dementia. Am J Geriatr Psychiatry 13, 116-123.

[9] Gatz M, Mortimer JA, Fratiglioni L, Johansson B, Berg S, Reynolds CA, Pedersen NL (2006) Potentially modifiable risk factors for dementia in identical twins. Alzheimers Dement $\mathbf{2}$, 110-117.

[10] Paajanen TA, Oksala NK, Kuukasjärvi P, Karhunen PJ (2010) Short stature is associated with coronary heart disease: A systematic review of the literature and a meta-analysis. Eur Heart J 31, 1802-1809.

[11] Janghorbani M, Momeni F, Dehghani M (2012) Hip circumference, height and risk of type 2 diabetes: Systematic review and meta-analysis. Obes Rev. 13, 1172-1181.

[12] Weitzman S, Wang CH, Pankow JS, Schmidt MI, Brancati FL (2010) Are measures of height and leg length related to incident diabetes mellitus? The ARIC (Atherosclerosis Risk in Communities) study. Acta Diabetol. 47, 237-242.

[13] Newman AB, Fitzpatrick AL, Lopez O, Jackson S, Lyketsos C, Jagust W, Ives D, Dekosky ST, Kuller LH (2005) Dementia and Alzheimer's disease incidence in relationship to cardiovascular disease in the cardiovascular health study cohort. J Am Geriatr Soc 53, 1101-1107.

[14] McCrimmon RJ, Ryan CM, Frier BM (2012) Diabetes and cognitive dysfunction. Lancet 379, 2291-2299

[15] Mortimer JA, Snowdon DA, Markesbery WR (2008) Small head circumference is associated with less education in persons at risk for Alzheimer disease in later life. Alzheimer Dis Assoc Disord 22, 249-254.
[16] Tisserand DJ, Bosma H, Van Boxtel M, Jolles J (2001) Head size and cognitive ability in nondemented older adults are related. Neurology, 56, 969-971.

[17] Mak Z, Kim JM, Stewart R (2006) Leg length, cognitive impairment and cognitive decline in an African-Caribbean population. Int J Geriatr Psychiatry, 21, 266-272.

[18] Perneczky R, Wagenpfeil S, Lunetta KL, Cupples LA, Green RC, Decarli C, Farrer LA, Kurz A; MIRAGE Study Group (2010) Head circumference, atrophy, and cognition: Implications for brain reserve in Alzheimer disease. Neurology 75, 137-142.

[19] Huang TL, Carlson MC, Fitzpatrick AL, Kuller LH, Fried LP, Zandi PP (2008) Knee height and arm span: A reflection of early life risk factors. Neurology 70, 1818-1826.

[20] Kumari M, Head J, Marmot M (2004) Prospective study of social and other risk factors for incidence of type 2 diabetes in the Whitehall II study. Arch Intern Med, 164, 1873-1880.

[21] Johnston LW, Harris SB, Retnakaran R, Gerstein HC, Zinman B, Hamilton J, Hanley AJ (2013) Short leg length, a marker of early childhood deprivation, is associated with metabolic disorders underlying type 2 diabetes: The PROMISE cohort study. Diabetes Care, 36, 3599-3606.

[22] Guerrero-Berroa E, Ravona-Springer R, Schmeidler J, Silverman JM, Sano M, Koifmann K, Preiss R, Hoffman H, Heymann A, Schnaider Beeri M (2014) Age, gender, and education are associated with cognitive performance in an older Israeli sample with type 2 diabetes. Int J Geriatr Psychiatry 29, 299-309.

[23] Ravona-Springer R, Heymann A, Schmeidler J, GuerreroBerroa E, Sano M, Preiss R, Koifman K, Hoffman H, Levy A, Silverman JM, Schnaider-Beeri M (2013) Haptoglobin 11 genotype is associated with poorer cognitive functioning in the elderly with type 2 diabetes. Diabetes Care 36, 3139-3145.

[24] Beeri MS, Ravona-Springer R, Moshier E, Schmeidler J, Godbold J, Karpati T, Leroith D, Koifman K, Kravitz E, Price R, Hoffman H, Silverman JM, Heymann A (2014) The Israel Diabetes and Cognitive Decline (IDCD) study: Design and baseline characteristics. Alzheimers Dement, doi: 10.1016/j.jalz.2014.06.002.

[25] Morris JC (1993) The Clinical Dementia Rating (CDR): Current version and scoring rules. Neurology 43, 2412-2414.

[26] Frongillo E (2004) Evaluating statistical interactions. StatNews \#64. Cornell Statistical Consulting Unit. Cornell University.

[27] Case A, Paxson C (2008) Height, health, and cognitive function at older ages. Am Econ Rev 98, 463-467.

[28] Stini WA (1969) Nutritional stress and growth: Sex difference in adaptive response. Am J Phys Anthropol 31, 417-426.

[29] Stinson S (1985) Sex differences in environmental sensitivity during growth and development. Am J Phys Anthropol 28, 123-147.

[30] Verloove-Vanhorick SP (1989) The male disadvantage in very low birthweight infants: Does it really exist? Eur J Pediatr 149, 197-202.

[31] Kirchengast S, Hartmann B (2009) The male disadvantage hypothesis reconsidered: Is there really a weaker sex? An analysis of gender differences in newborn somatometrics and vital parameters. J Life Sci 1, 63-71.

[32] Arenaza-Urquijo EM, Landeau B, La Joie R, Mevel K, Mézenge F, Perrotin A, Desgranges B, Bartrés-Faz D, Eustache F, Chételat G (2013) Relationships between years of education and gray matter volume, metabolism and functional connectivity in healthy elders. Neuroimage 83, 450-457.

[33] Snowdon DA, Kemper SJ, Mortimer JA, Greiner LH, Wekstein DR, Markesbery WR (1996) Linguistic ability in early 
life and cognitive function and Alzheimer's disease in late life. Findings from the Nun Study. JAMA 275, 528-532.

[34] Barker DJ, Hales CN, Fall CH, Osmond C, Phipps K, Clark PM (1993) Type 2 (non-insulin-dependent) diabetes mellitus, hypertension and hyperlipidaemia (syndrome X): Relation to reduced fetal growth. Diabetologia 36, 62-67.

[35] Barker DJ, Martyn CN (1992) The maternal and fetal origins of cardiovascular disease. J Epidemiol Community Health 46, $8-11$.

[36] Singh-Manoux A, Marmot MG, Glymour M, Sabia S, Kivimäki M, Dugravot A (2011) Does cognitive reserve shape cognitive decline? Ann Neurol 70, 296-304.

[37] Weinstein G, Goldbourt U, Tanne D (2013) Body height and late-life cognition among patients with atherothrombotic disease. Alzheimer Dis Assoc Disord 27, 145-152.
[38] Graham NL, Emery T, Hodges JR (2004) Distinctive cognitive profiles in Alzheimer's disease and subcortical vascular dementia. J Neurol Neurosurg Psychiatry 75, 61-71.

[39] Goldbourt U, Tanne D (2002). Body height is associated with decreased long-term stroke but not coronary heart disease mortality? Stroke 33, 743-748.

[40] Smith PJ, Blumenthal JA, Babyak MA, Hoffman, BM, Doraiswamy PM, Waugh R, Hinderliter A, Sherwood A (2007) Cardiovascular risk factors, vascular disease, and neuropschological outcomes in adults with major depression. Psychosom Med 69, 578-586. 